\title{
Grafe Fruit Extract (Vitis Vinifera) As An Antioxidant
}

\author{
Hartono $^{1}$, I Nyoman Ehrich Lister ${ }^{2 *}$, Buter Samin ${ }^{3}$ \\ ${ }^{1,2,3}$ Faculty of Medicine, Universitas Prima Indonesia \\ * Corresponding author: \\ Email: nyoman@unprimdn.ac.id
}

\begin{abstract}
One plant that is believed to have anti-diabetic effects is grapes (Vitis vinifera), which contains polyphenol compounds. The antioxidant and anti-postprandial hyperglycemics of grape extract show potential in treating diabetes. This study is an experimental study that aims to explore grape extract extracts as antioxidants through testing (DPPH, ABTS, LC-MS/MS). Based on the test results, grape extract contains very high phytochemicals, including terpenoids and alkaloids, and antioxidant test results found DPPH with an average IC50 value of $21.49 \mathrm{~g} / \mathrm{mL}$ and at the lowest concentration $(6.25 \mathrm{~g} / \mathrm{mL})$. The GFE also showed the highest antioxidant activity against ABTS trapping with an average IC50 value of $74.07 \mathrm{~g} / \mathrm{mL}$ and $L C-M S / M S$ results obtained grape extract samples containing $0.00001 \%$ chlorogenic acid and querce-tin compounds of $0.00012 \%$.
\end{abstract}

Keywords: Vitis vinivera, antioksidan, DPPH, ABTS, LC-MS/MS.

\section{INTRODUCTION}

Oxidative stress plays an important role in the pathophysiology of aging processes and various degenerative diseases, such as cancer, diabetes mellitus and its complications, as well as atherosclerosis underlying heart disease, blood vessels and stroke.1,2,3 Antioxidants are indispensable by the body to overcome and prevent oxidative stress. Various natural ingredients native to Indonesia contain many antioxidants with various active ingredients. The use of native natural ingredients found in Indonesia as antioxidants is needed to improve the quality of public health at a relatively more affordable cost. Free radicals are unstable atoms with the outermost electrons that are unpaired and highly reactive. Free radicals always try to form stable bonds, by gaining or losing unpaired electrons (4)Antioxidants are needed to protect the body from free radical attacks.

Antioxidants have the ability to donate electrons and can serve as a reducing agent so that they can hold metal ions and reduce the potential for radicals in the body (5).Antioxidant ingredients are known to have side effects in varying degrees, but in general ingredients sourced from nature have relatively smaller side effects. Antioxidant ingredients can be obtained from plants that contain phenolic or polyphenolic compounds, such as flavonoids (6). One plant that is believed to have antioxidant effects is grapes (Vitis vinifera), which contains polyphenol compounds. The antioxidant and anti-postprandial hyperglycemics of grape extract show potential in treating a wide variety of diseases. 11 Grapes also contain resveratol compounds that have high antioxidant activity and can protect cells $\beta$ pancreas, increase insulin secretion, and lower insulin resistance (7). Ekstrak buah anggur yang digunakan dalam diet tinggi lemak dapat mencegah obesitas dengan mempengaruhi metabolisme lipid pada tikus (8).

\section{MATERIALS AND METHODS}

This research is an experimental study that aims to explore Grafe Fruit Extract as an antioxidant agent using Post-Test Only Control Group Design. This research was conducted in vitro using grafe fruit extract.

\section{RESULTS AND DISCUSSION \\ In Vitro Test Results \\ DPPH Antioxidant Test Results (2,2-diphenyl-1-picrylhydrazyl-hydrate)}




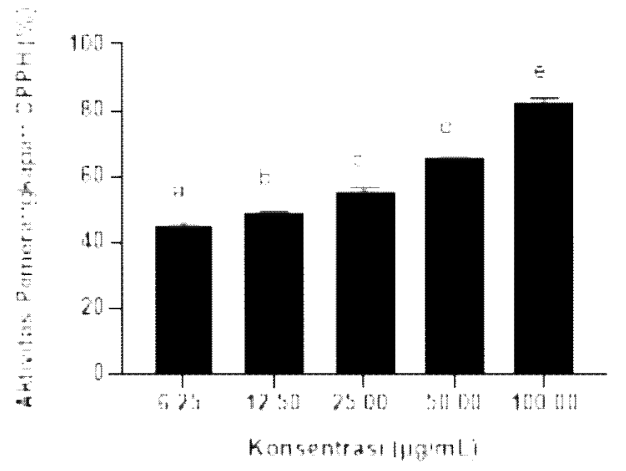

Fig 1. Effect of Grape Extract on DPPH . Antioxidant Activity

*Data are presented in mean $\pm \mathrm{SD}$. Superscript sign differences (a, b, c, d, e) showed significant differences $(\mathrm{p}<0.05)$ Tukey HSD post hoc test

Based on the measurement results, it can be seen that the antioxidant activity of GFE in DPPH increased along with the decrease in the concentration of the extract. At the lowest concentration $(6.25 \mathrm{~g} / \mathrm{mL})$, GFE showed the highest antioxidant activity against DPPH trapping with an average IC50 value of $21.49 \mathrm{~g} / \mathrm{mL}$. These results indicate that GFE has antioxidant activity on DPPH radicals.

\section{ABTS Antioxidant Test Results (2,2'-Azinobis(3-Ethylbenzthiazoline-6-Sulfonate))}

ABTS antioxidant activity test (2,2'-Azinobis(3-Ethylbenzthiazoline-6-Sulfonate)) was based on the reaction of antioxidant compounds and ABTS. Antioxidant compounds will reduce the blue-green color formed in the ABTS solution. ABTS solution is produced from the reaction of a strong oxidizing agent (potassium permanganate or potassium persulfate) with ABTS salt. Antioxidant compounds will donate hydrogen atoms and reduce ABTS radicals. The color change in the solution was measured at a wavelength of $745 \mathrm{~nm}$. The results of the measurement of the percentage of trapping activity and the IC50 value of GFE can be seen in table 2.3 and presented in Figure 2.3.

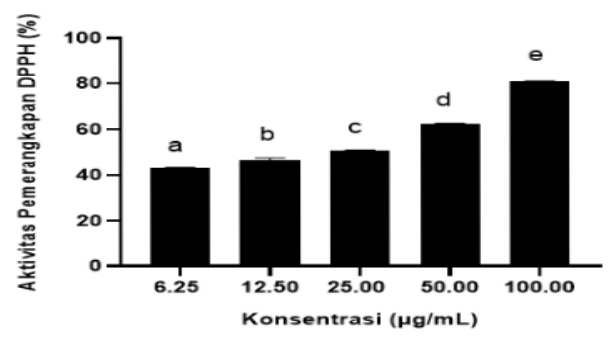

Fig 3. Effect of Grape Extract on Antioxidant Activity of ABTS

*Data are presented in mean $\pm \mathrm{SD}$. Different superscript marks (a, b, c, d, e) showed significant differences $(\mathrm{p}<0.05)$ Tukey HSD post hoc test.

Based on the measurement results, it can be seen that the antioxidant activity of GFE in ABTS increased along with the decrease in the concentration of the extract. At the lowest concentration $(6.25 \mathrm{~g} / \mathrm{mL})$, GFE showed the highest antioxidant activity against ABTS trapping with an average IC50 value of $74.07 \mathrm{~g} / \mathrm{mL}$.

\section{LC-MS/MS Test Results Grape Fruit Extract}

LC separates the components of the compounds in the sample based on their relative interactions with the stationary phase and the elution of the solvent through the column (mobile phase). The advantage of LC-MS is that it can analyze a wider range of components, such as thermally labile compounds, high polarity or high molecular mass, and even proteins. The standard chromatogram of grape seed extract is shown in Figure 2. 


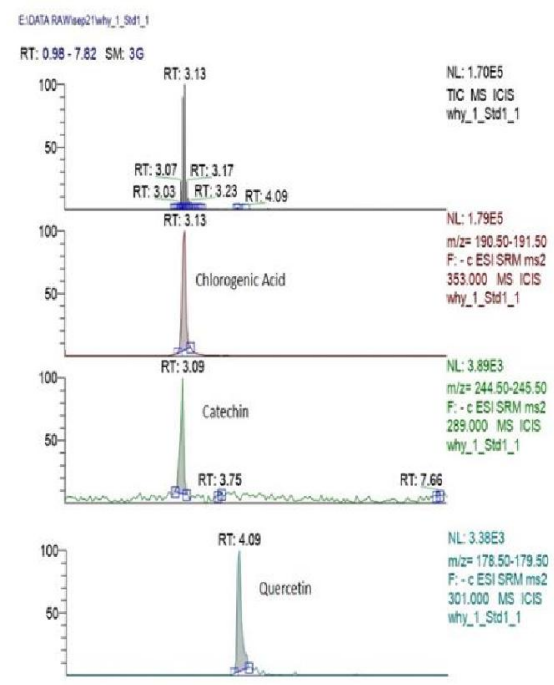

Fig 2. Standard Chromatogram of Grape Extract

TIC or total ion chromatogram is a combined chromatogram of standard mixtures (chlorogenic acid, catechins, and quercetin). Different compounds will give peaks at different retention times so that their presence in the mixture can be identified. In Figure 2, the standard mixture of chlorogenic acid 1 is identified at RT (Retention Time) 3.13, catechins at 3.09, and quercetin at 4.09. While in Figure 2. shows that in grape extract chlorogenic acid was identified at RT (Retention Time) 3.13 and quercetin at 4.09, while catechins were not identified.

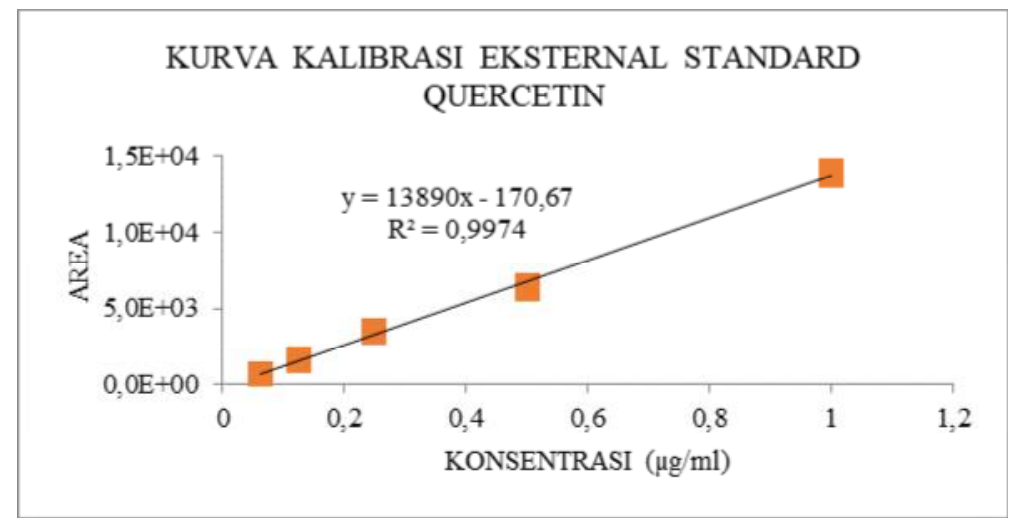

Fig 3. Quercetin . Standard Curve

Based on the results obtained, it can be concluded that the grape extract samples contain chlorogenic acid compounds of $0.00001 \%$ and quercetin compounds of $0.00012 \%$. Mass spectrophotometry (MS) is an analytical technique used to determine the presence of compounds based on their molecular weight. The working principle used is the bombardment of organic compound molecules with electron beams so that these compounds can be ionized. The magnetic field will bend the ion so that its molecular weight can be determined. The charge induced when the ions hit the surface will be calculated by the detector in terms of the mass-to-charge ratio $(\mathrm{m} / \mathrm{z})$.

The results showed that EBK contained several compounds as shown in Table 2. GFE contained pinobaksin-3-o-phenylpropionate, apigenin-o-rutinoside, and quercetin dimethyl ether-3-o-rutinoside compounds.

Table 2. Identification of Target Compounds of Grape Extract with ESI-MS

\begin{tabular}{|l|c|c|}
\hline Grapes & MW (g/mol) & MS [MH]- (m/z) \\
\hline Dimer 1 (paffidol) & 454 & 453.872 \\
\hline resveratrol methyl ether & 228.25 & 241,690 \\
\hline
\end{tabular}




\section{CONCLUSION}

1. GFE contains very high phytochemicals, including terpenoids and alkaloids

2. The antioxidant activity of EBA in DPPH increases along with the decreased concentration of the extract. At the lowest concentration $(6.25 \mu \mathrm{g} / \mathrm{mL})$, the GFE showed the highest antioxidant activity against DPPH exposure with an average IC50 value of $21.49 \mu \mathrm{g} / \mathrm{mL}$. The results showed that EBA has antioxidant activity in DPPH radicals.

3. The antioxidant activity of EBA in ABTS increases along with the decreased concentration of the extract. At the lowest concentration $(6.25 \mu \mathrm{g} / \mathrm{mL})$, the GFE showed the highest antioxidant activity against abts with an average IC50 value of $74.07 \mu \mathrm{g} / \mathrm{mL}$.

4. LC-MS/MS results obtained by GFE contain $0.00001 \%$ chlorogenic acid and querce-tin compounds of $0.00012 \%$.

\section{REFERENCE}

[1] Setiati S. Radikal bebas, antioksidan, dan proses menua. Medika 2003; 6:366-9.

[2] Shihabi A, Li WG, Miller Jr FG, Weintraub NL. Antioxidant therapy for atherosclerotic vascular disease: the promise and the pitfalls. Am J Physiol Heart Circ Physiol [serial online]. 2002 [disitasi bulan Maret 2009]; 282 (3): 797-802.

[3] Giacco F, Brownlee M. Oxidative Stress and Diabetic Complications. Circ Res [serial online]. 2010 [disitasi tanggal 29 July 2013];107:1058-70.

[4] Ramamurthy et al, 2013 Ramamurthy, C., Sampath, K. S., Arunkumar, P., Suresh Kumar, M., Sujatha, V., Premkumar, K., and Thirunavukkarasu, C. (2013). Green synthesis and characterization of selenium nanoparticles and its augmented cytotoxicity with doxorubicin on cancer cells. Bioprocess and Biosystems Engineering, 36(8), 1131-1139.

[5] Vaya dan Aviram, 2001. Vaya, J, Aviram, M. 2001. Nutritional antioxidant : mechanism of action, analyses of activities and medical applications, Curr. Med. ChemImm,Endoc. \&Metab Agents

[6] Papas, 1999; Halliwel dan Gutteridge, 1999. Papas, A.M. 1999. Antioxidant Status, Diet,

[7] Sun, C., Liu, Y., Zhan, L., Rayat, G. R., Xiao, J., Jiang, H., Chen, K. Anti-diabetic effects of natural antioxidants from fruits. Trends in Food Science \& Technology. 2020

[8] Gourineni, Vishnupriya \& Shay, Neil \& Chung, Soonkyu \& Sandhu, Amandeep \& Gu, Liwei. Muscadine Grape (Vitis rotundifolia) and Wine Phytochemicals Prevented Obesity- Associated Metabolic Complications in C57BL/6J Mice. Journal of agricultural and food chemistry. 2012; 60. 7674-81. 10.1021 